\title{
A Rare Case of Takotsubo Cardiomyopathy in a Patient With No Identifiable Emotional or Physical Stressors
}

\author{
Swann Tin ${ }^{1}$, William Lim $^{1}$, Anum Humayun ${ }^{2}$, Sean Galligan ${ }^{3}$ \\ 1. Internal Medicine, Richmond University Medical Center, Staten Island, USA 2. Internal Medicine, Richmond \\ University Medical Center, new york, USA 3. Internal Medicine/Cardiology, Richmond University Medical Center, \\ Staten Island, USA
}

Corresponding author: Swann Tin, swannhtet2298@gmail.com

\begin{abstract}
Takotsubo cardiomyopathy (TCM) is a cardiac condition that presents with features of acute myocardial infarction and transient systolic dysfunction without angiographic findings of obstructive coronary heart disease. Common presenting symptoms include acute substernal chest pain, dyspnea and syncope. It is usually triggered by recent emotional or physical stress such as head trauma, stroke, sepsis, overproduction of catecholamines such as pheochromocytoma or following Myasthenia crisis. We are here to report a case of TCM who does not have any identifiable emotional or physical stress prior to the event. The patient was a 76-year-old Caucasian female with a past medical history of hypertension who presented to the hospital with chest pain which initially was treated as non-ST elevation myocardial infarction (NSTEMI) with aspirin, ticagrelor and heparin infusion. Cardiac catheterization later revealed non-obstructive coronary artery disease but showed akinesis of inferior, apical and anterior walls with hyperdynamic basal segments indicating TCM.
\end{abstract}

Review began 08/07/2021 Review ended 08/15/2021 Published 08/18/2021

(c) Copyright 2021 Tin et al. This is an open access article distributed under the terms of the Creative Commons Attribution License CC-BY 4.0., which permits unrestricted use, distribution, and reproduction in any medium, provided the original author and source are credited.
Categories: Cardiology, Internal Medicine

Keywords: takotsubo cardiomyopathy, stressors, chest pain, stress induced cardiomyopathy, left ventricular systolic dysfunction

\section{Introduction}

Takotsubo cardiomyopathy (TCM) is a cardiac condition that presents with features of acute myocardial infarction and transient systolic dysfunction without angiographic findings of obstructive coronary heart disease. It is also recognized as broken heart syndrome or stress-induced cardiomyopathy. It usually occurs in elderly individuals following a stressful psychological or physical event.

\section{Case Presentation}

A Caucasian female, 76 years, was brought into the emergency room (ER) for a sudden onset mid-sternal chest pain for six days. The pain was intermittent and dull in nature and associated with intermittent palpitations. There were no alleviating or exacerbating factors or any recent stressful events prior to the episode. The patient also has a past medical history of hypertension. She denied any shortness of breath, diaphoresis, dizziness, lightheadedness, dyspnea on exertion, orthopnea, paroxysmal nocturnal dyspnea or extremity edema. She reported being able to walk long distances without feeling short of breath. She denied any family history of cardiac disease or sudden cardiac death. In terms of her social history, she denied any cigarette smoking and illicit drug use but did report social alcohol drinking.

Upon arrival to ER, her initial vital signs were blood pressure of $164 / 99 \mathrm{mmHg}$, heart rate of 70/min, and her oxygen saturation was $98 \%$ on room air. Physical examination was essentially normal. Her initial troponin was elevated at 1.1 which further went up to 2.39 in the next three hours. Electrocardiogram (EKG) (Figure 1) showed left axis deviation with prolonged QTc of 564 milliseconds with T-wave inversions in inferior leads (lead II, III and aVF) and anterolateral chest leads (from V3 to V6). Non-ST elevation myocardial infarction (NSTEMI) treatment was initiated in ER and the patient was loaded with aspirin $162 \mathrm{mg}$, ticagrelor $180 \mathrm{mg}$ and continuous heparin IV infusion. 


\section{Cureus}

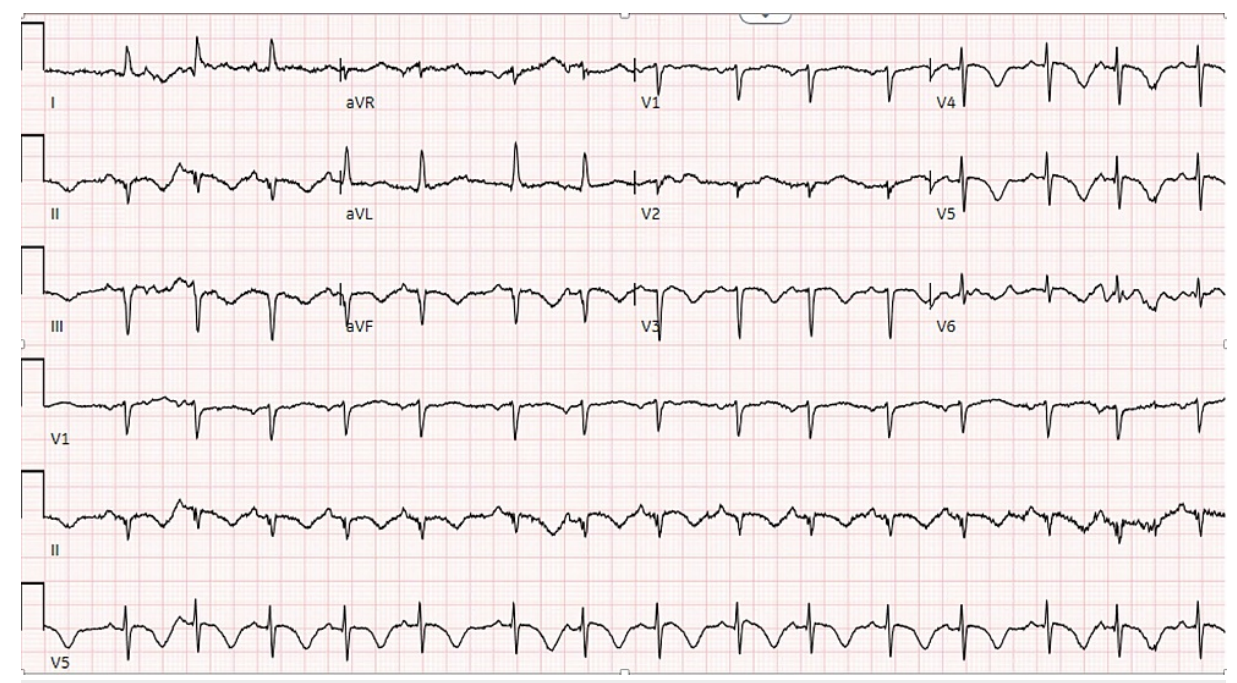

FIGURE 1: Electrocardiogram (EKG) showing T-wave inversions in inferior leads (lead II, III and aVF) and anterolateral chest leads (V3 to V6)

An echocardiogram showed moderate left ventricular systolic dysfunction with ejection fraction (EF) of 30\%$35 \%$. She then underwent a cardiac catheterization (Figure 2), which revealed no obstructive coronary artery disease but showed akinesia of inferior, apical and anterior wall with hyper-dynamic basal segments with apical ballooning indicating TCM.

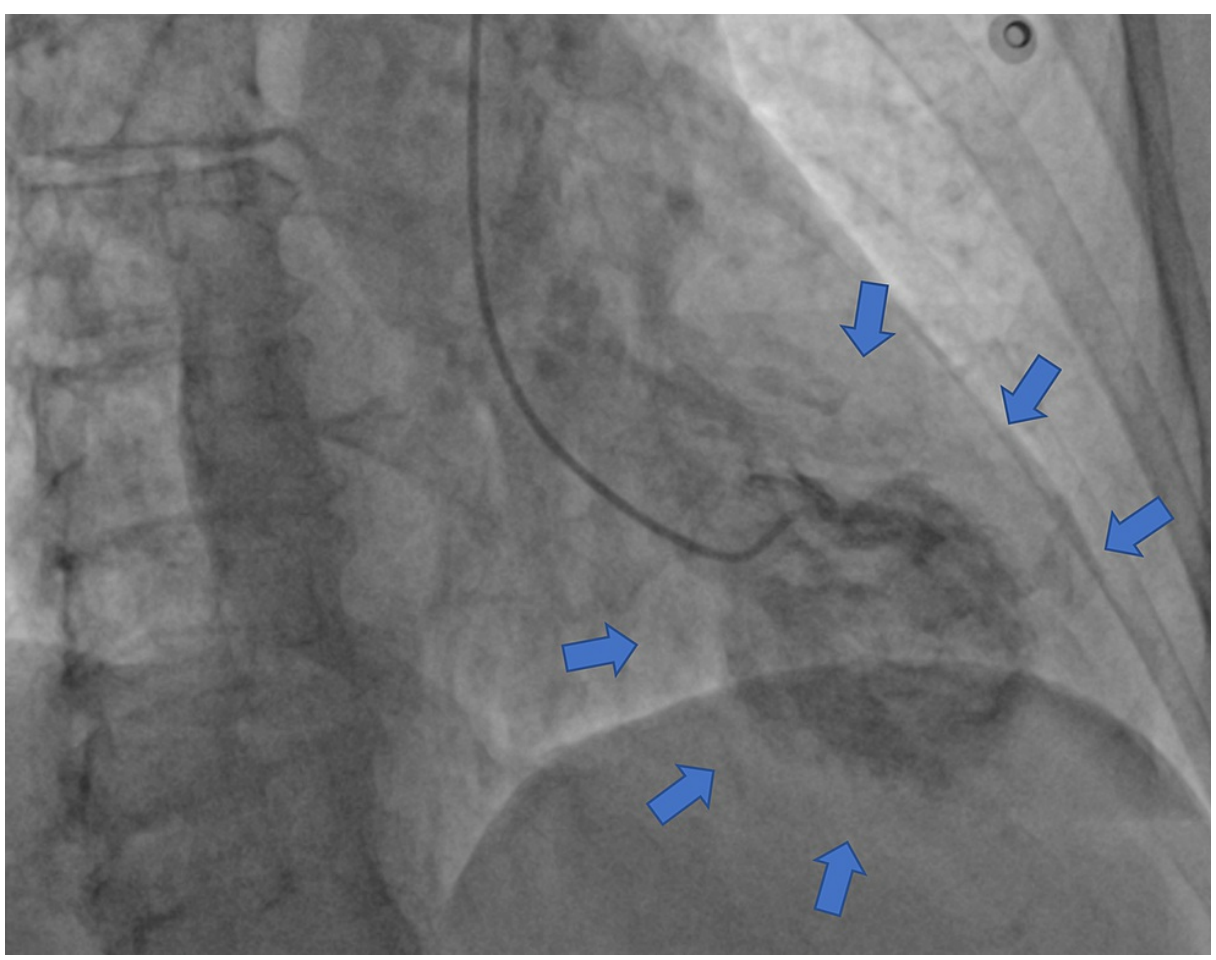

FIGURE 2: Left ventricular angiogram demonstrating the left ventricle (LV) ballooning (Takotsubo cardiomyopathy or apical ballooning syndrome)

Guideline-directed medical therapy was initiated with metoprolol and lisinopril for low EF (EF <40\%). The patient was discharged on the next day and instructed to follow up with the cardiology clinic in 1-2 weeks and to repeat an echocardiogram in 3-6 months. 


\section{Discussion}

TCM is an acute cardiac condition that presents with symptoms of acute myocardial infarction and transient left ventricular dysfunction without underlying obstructive coronary artery disease [1-3]. It is commonly seen as apical ballooning of the left ventricle on angiogram which has a close resemblance to a Japanese octopus pot [4]. "Tako" means "octopus" and "tsubo" means "pot." Current data suggest that it accounts for $2 \%$ of patients presenting to the ER with suspected acute coronary syndrome [5]. The incidence is frequently triggered by intense emotional or physical stress [6,7]. Recent studies also noted that the prevalence of TCM following Myasthenia crisis is 15 times higher than the general population [8], and it has increased morbidity and mortality in patients with cannabis use [9]. Our patient here presented with substernal chest pain with elevated troponin levels, which was initially thought to have an acute coronary syndrome. There was no known emotional or physical stress prior, which makes the diagnosis more challenging.

Even though the precise mechanism that causes stress cardiomyopathy is unknown, postulated mechanisms involve diffuse catecholamine-induced microvascular spasm or dysfunction and direct catecholamineassociated myocardial toxicity [7,10]. Common presenting symptoms are acute substernal chest pain, dyspnea and syncope [11]. Common EKG abnormalities found are ST elevation, ST depression, QT interval prolongation, $\mathrm{T}$ wave inversion and abnormal $\mathrm{Q}$ waves [12]. A transthoracic echocardiogram (TTE) can identify wall-motion abnormalities, especially akinesis or hypokinesis of the apical segment of the left ventricle. The diagnosis can be confirmed with a cardiac angiogram, which reveals no evidence of obstructive coronary vasculature or no signs of plaque rupture [13].

TCM usually improves with conservative management along with the resolution of underlying stressful conditions. Currently, there is no definitive therapy established for this disorder and supportive therapy remains the mainstay of treatment. The 2014 American Heart Association/American College of Cardiology guidelines recommended angiotensin-converting-enzyme inhibitors, beta-blockers, diuretics and aspirin for these patients if they are hemodynamically stable [14]. TCM also has a risk of recurrent attack; however, the appropriate strategy for long-term medical therapy and their effectiveness in preventing recurrence is unclear. For patients with stress cardiomyopathy with intraventricular thrombus, anticoagulation therapy is recommended for a total of three months [15].

TCM is a reversible condition; however, it has considerable rates of death and complications after the acute phase of the disease. According to a recent TCM registry, the rates of death and of stroke/transient ischemic attack are $5.6 \%$ and $1.7 \%$ per patient-year, respectively [11].

\section{Conclusions}

TCM is a transient medical problem that can mimic an acute coronary syndrome. It has a favorable prognosis and the left ventricular hypokinesis usually improves within a few weeks. However, in some cases, it is associated with serious complications such as hypotension, shock, heart failure, thromboembolism and stroke. Therefore, it is important for physicians to be familiar with various presentations of stress cardiomyopathy and appropriate treatment.

\section{Additional Information}

\section{Disclosures}

Human subjects: Consent was obtained or waived by all participants in this study. Conflicts of interest: In compliance with the ICMJE uniform disclosure form, all authors declare the following: Payment/services info: All authors have declared that no financial support was received from any organization for the submitted work. Financial relationships: All authors have declared that they have no financial relationships at present or within the previous three years with any organizations that might have an interest in the submitted work. Other relationships: All authors have declared that there are no other relationships or activities that could appear to have influenced the submitted work.

\section{References}

1. Bybee KA, Kara T, Prasad A, Lerman A, Barsness GW, Wright RS, Rihal CS: Systematic review: transient left ventricular apical ballooning: a syndrome that mimics ST-segment elevation myocardial infarction. Ann Intern Med. 2004, 141:858-65. 10.7326/0003-4819-141-11-200412070-00010

2. Tsuchihashi K, Ueshima K, Uchida T, et al.: Transient left ventricular apical ballooning without coronary artery stenosis: a novel heart syndrome mimicking acute myocardial infarction. J Am Coll Cardiol. 2001, 38:11-8. 10.1016/s0735-1097(01)01316-X

3. Abe Y, Kondo M, Matsuoka R, Araki M, Dohyama K, Tanio H: Assessment of clinical features in transient left ventricular apical ballooning. J Am Coll Cardiol. 2003, 41:737-42. 10.1016/s0735-1097(02)02925-X

4. Akashi YJ, Nef HM, Möllmann H, Ueyama T: Stress cardiomyopathy. Annu Rev Med. 2010, 61:271-86. 10.1146/annurev.med.041908.191750

5. Akashi YJ, Nef HM, Lyon AR: Epidemiology and pathophysiology of Takotsubo syndrome. Nat Rev Cardiol. 2015, 12:387-97. 10.1038/nrcardio.2015.39

6. Sharkey SW, Lesser JR, Zenovich AG, Maron MS, Lindberg J, Longe TF, Maron BJ: Acute and reversible cardiomyopathy provoked by stress in women from the United States. Circulation. 2005, 111:472-9. 


\section{Cureus}

10.1161/01.CIR.0000153801.51470.EB

7. Wittstein IS, Thiemann DR, Lima JA, et al.: Neurohumoral features of myocardial stunning due to sudden emotional stress. N Engl J Med. 2005, 352:539-48. 10.1056/NEJMoa043046

8. Desai R, Desai A, Fong HK, et al.: Prevalence, trends and in-hospital outcomes of takotsubo syndrome among United States cannabis users. Int J Cardiol. 2020, 316:43-6. 10.1016/j.ijcard.2020.05.088

9. Desai R, Abbas SA, Fong HK, et al.: Burden and impact of takotsubo syndrome in myasthenic crisis: a national inpatient perspective on the under-recognized but potentially fatal association. Int J Cardiol. 2020, 299:63-6. 10.1016/i.ijcard.2019.09.054

10. Paur H, Wright PT, Sikkel MB, et al.: High levels of circulating epinephrine trigger apical cardiodepression in a 32 -adrenergic receptor/Gi-dependent manner: a new model of Takotsubo cardiomyopathy. Circulation. 2012, 126:697-706. 10.1161/CIRCULATIONAHA.112.111591

11. Templin C, Ghadri JR, Diekmann J, et al.: Clinical features and outcomes of Takotsubo (Stress) cardiomyopathy. N Engl J Med. 2015, 373:929-38. 10.1056/NEJMoa1406761

12. Ogura R, Hiasa Y, Takahashi T, et al.: Specific findings of the standard 12-lead ECG in patients with 'Takotsubo' cardiomyopathy: comparison with the findings of acute anterior myocardial infarction. Circ J. 2003, 67:687-90. 10.1253/circj.67.687

13. Koeth O, Mark B, Kilkowski A, et al.: Clinical, angiographic and cardiovascular magnetic resonance findings in consecutive patients with Takotsubo cardiomyopathy. Clin Res Cardiol. 2008, 97:623-7. 10.1007/s00392008-0661-X

14. Amsterdam EA, Wenger NK, Brindis RG, et al.: 2014 AHA/ACC guideline for the management of patients with non-ST-elevation acute coronary syndromes: a report of the American College of Cardiology/American Heart Association Task Force on Practice Guidelines. J Am Coll Cardiol. 2014, 64:e139-228. 10.1016/i.jacc.2014.09.017

15. Management and prognosis of stress (takotsubo) cardiomyopathy. (2020). Accessed: July 1, 2021: http://cardiomyopathyhttps://www.uptodate.com/contents/management-and-prognosis-of-stresstakotsubo-cardiomyopathy. 